\title{
Nitrogen study fertilizes fears of pollution
}

Jim Giles, London

Urgent political and scientific action is needed to tackle the global threat of nitrogen pollution, say scientists behind one of the field's biggest research projects.

They gathered in London last week to mark the completion of a five-year, $\mathfrak{E} 7$-million (US\$13-million) project to map the effects of excess nitrogen on forests, rivers and grasslands, primarily in Britain.

The researchers say that the Global Nitrogen Enrichment (GANE) programme has transformed their understanding of how nitrogen affects the environment. But a lack of similar studies in other countries has led to inadequate legislation, which is generating a growing threat to global biodiversity, they say. Previous efforts have been made to draw attention to the issue, but researchers say that much more needs to be done.

Since the Industrial Revolution, humans have been converting unreactive nitrogen gas from the atmosphere into reactive forms such as ammonia, primarily for use in fertilizers (see graph). These industrial processes have revolutionized food production, but, along with the release of other reactive forms of nitrogen from the burning of fossil fuels, they have led to a massive increase in the amount of reactive nitrogen in circulation.

"This is the third major threat to our planet after biodiversity loss and climate change," says John Lawton, chief executive of the Natural Environment Research Council, which provided the bulk of the funding for GANE. "It's manifestly unsustainable in the long term."

Excess nitrogen is known to have a variety of ill effects on plant life. Parts of the Gulf of Mexico, for example, are so inundated with excess fertilizer that the water is clogged with algae, suffocating fish and other marine life.

GANE researchers wondered whether a detrimental effect is also occurring in freshwater lakes. They surveyed 60 shallow freshwater lakes in Britain and Poland to see whether dissolved nitrate ions are involved in observed losses of plant life. Brian Moss, an ecologist at the University of Liverpool, who led the study, says the result is clear: "More nitrate means fewer species."

Nitrate ions tend to boost the growth of one or two plant species, says Moss, which go on to dominate the lake. If these dominant species are lost, perhaps during a cold snap, algae can take over and prevent any plant life from returning. Phosphorus is known to have this effect, and the GANE results suggest that nitrogen is equally important.

Moss fears that European regulations on nitrates are too lax to prevent further plant loss. In Britain, for example, government regulations stipulate that nitrogen in nitrate ions in water must not exceed 10.3 milligrams

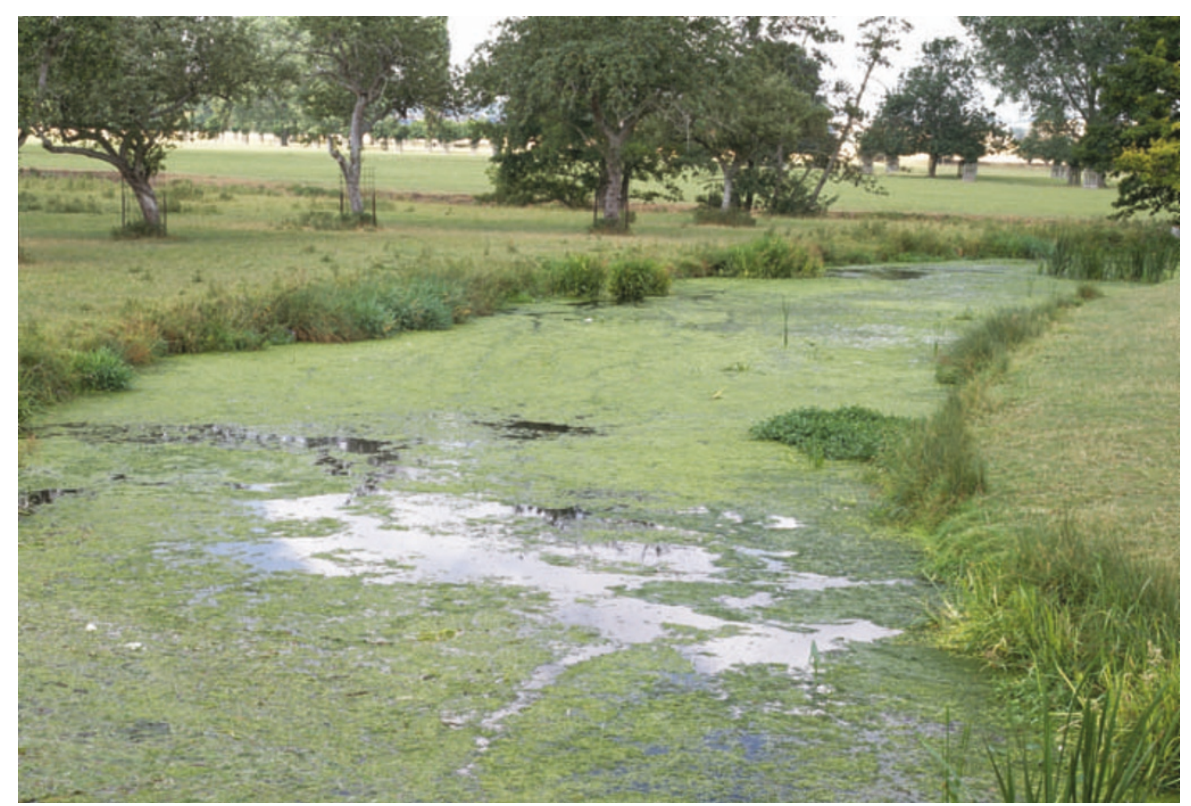

Spreading menace: nitrogen-based fertilizers enter rivers and cause them to become choked by algae.

per litre, primarily for reasons to do with human health. But according to Moss, levels of 2-3 milligrams per litre can wipe out all but a few species from most shallow lakes.

The results will not be published until later this year, but Moss says he made the UK government aware of the finding two years ago. A spokesman for the Department for Environment, Food and Rural Affairs says that nitrogen research is a "developing area of

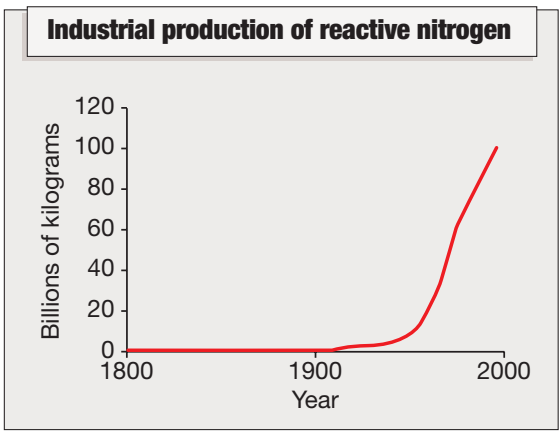

Global production of nitrogen-based fertilizers and explosives has been rising dramatically.

science" and that government policy cannot be revised until more is known about the impact of nitrogen on freshwater ecology.

The conference also heard evidence that nitrogen levels are linked with sometimes subtle changes in grassland species, from mosses and lichens to grasses and flowers. GANE scientists urged the government to take account of these results, but lamented that similar data are not available for other parts of the world that face a similar threat.

The forests of the Great Smoky Mountains on the border of Tennessee and North
Carolina is one such area, says Alan Davison, an expert in air pollution at the University of Newcastle upon Tyne, UK, and scientific coordinator for GANE. "There are 120 species of tree there - equivalent to the whole of Europe," he says. Nitrogen levels in the area are known to be high, he adds, and there is evidence from other forests that this could be detrimental (see Nature 425, 894-895; 2003).

Other biodiversity hotspots may also be threatened. Europe and North America have previously been the biggest sources of reactive nitrogen, but by 2020 half of anthropogenic nitrogen is expected to come from developing nations, which are home to many of the world's most species-rich areas.

Nitrogen pollution has not been properly measured in many of these regions. An attempt to estimate the nitrogen load on biodiversity hotspots has been completed, although the research team, led by University of Sheffield plant biologist Gareth Phoenix, has declined to reveal details until its paper has been peer reviewed.

Other groups are also trying to raise the issue's political profile. The International Nitrogen Initiative promotes cooperation on nitrogen research, and last year produced a review summarizing the predicted impact of global nitrogen pollution.

The group's chair, biogeochemist James Galloway of the University of Virginia in Charlottesville, is also one of the researchers behind the Nanjing Declaration on nitrogen management. This document, which was signed by scientists last October in Nanjing, China, calls on the United Nations to promote nitrogen research and to consider policy responses. 